Provided for non-commercial research and education use. Not for reproduction, distribution or commercial use.

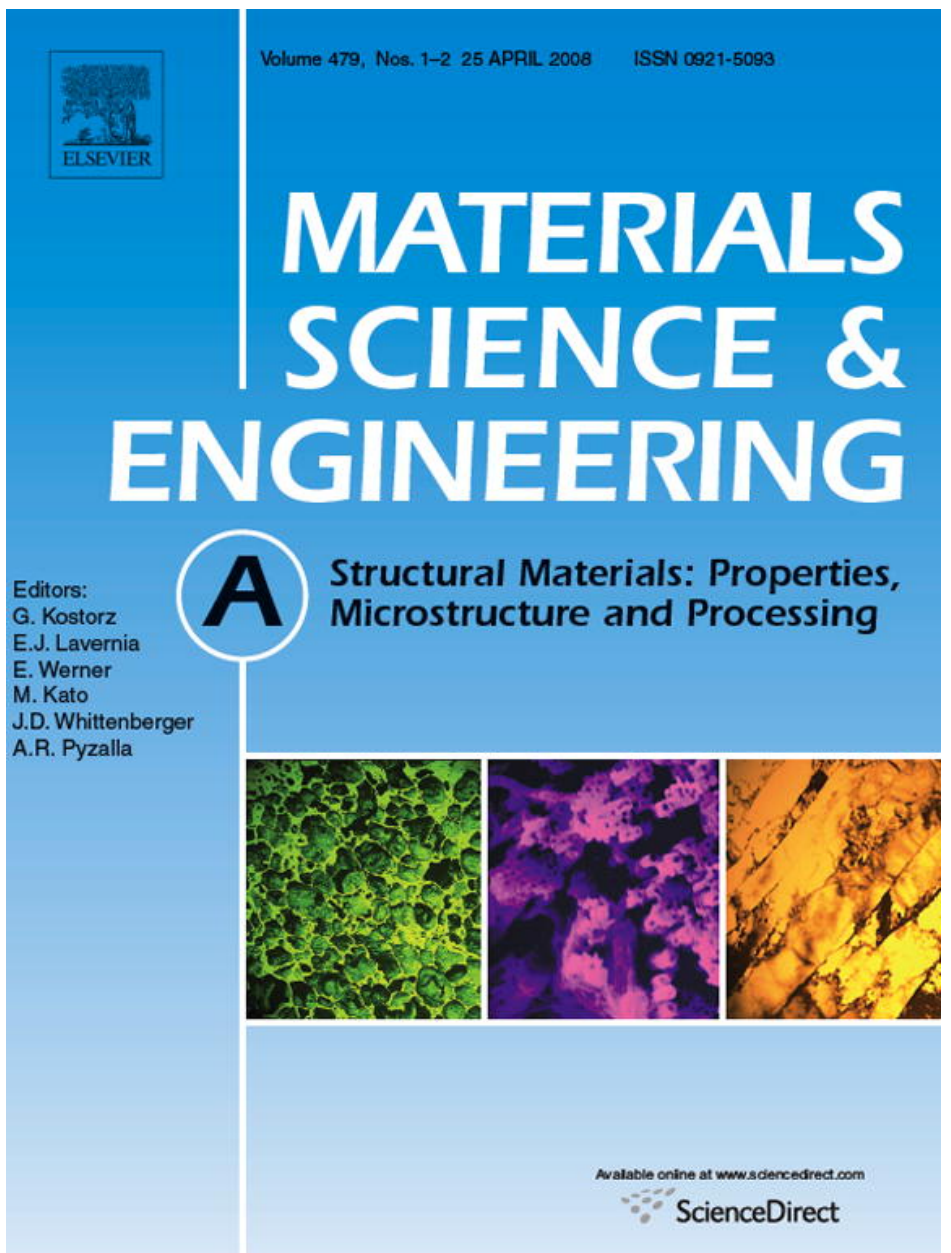

This article was published in an Elsevier journal. The attached copy

is furnished to the author for non-commercial research and education use, including for instruction at the author's institution, sharing with colleagues and providing to institution administration.

Other uses, including reproduction and distribution, or selling or licensing copies, or posting to personal, institutional or third party websites are prohibited.

In most cases authors are permitted to post their version of the article (e.g. in Word or Tex form) to their personal website or institutional repository. Authors requiring further information regarding Elsevier's archiving and manuscript policies are encouraged to visit: 


\title{
Grain structure and homogeneity of pulsed laser treated surfaces on Al-aerospace alloys and FSWs
}

\author{
P. Ryan ${ }^{1}$, P.B. Prangnell* \\ Manchester Materials Science Centre, The University of Manchester, \\ Grosvenor Street, Manchester M1 7HS, UK \\ Received 18 January 2007; accepted 12 June 2007
}

\begin{abstract}
The effect of pulsed excimer laser surface treatment, on typical Al-aerospace alloys and friction stir weld substrates, has been studied. A thin $<10 \mu \mathrm{m}$ deep surface layer can be achieved, where the majority of the re-solidified material does not exhibit phase separation, and has a higher level of homogeneity relative to the substrate material. However, due to the extremely short melt times, the layer is not as homogeneous as has previously been claimed and melted constituent particles leave solute rich trails throughout the layer. The treated layer also contains a series of second phase bands that are the result of a transient region, caused by the growth front from each pulse initially accelerating through speeds below ultimate stability, combined with the effects of composition variations within the liquid from the solute trails. The layer was further found to develop a grain structure that was very sensitive to that of the substrate and the presence of $\mathrm{Al}_{3} \mathrm{Zr} \beta^{\prime}$ dispersoids within the treated alloy, which can alter the grain structure from coarse epitaxial, to very fine columnar.
\end{abstract}

(C) 2007 Elsevier B.V. All rights reserved.

Keywords: Pulsed laser surface treatment; Laser surface melting; Excimer laser; Aluminium aerospace alloys; Corrosion; Rapid solidification; Epitaxial nucleation; Friction stir welding; Cellular-planar transition

\section{Introduction}

Aluminium airframes are currently protected against corrosive attack using treatments containing hexavalent chromium. Because this chemical is highly toxic and potentially damaging to the environment, it is in the process of being phased out of use, resulting in an urgent demand for replacement treatment systems [1]. Furthermore, with the introduction of welded structures in aircraft [2] local treatments are also required to protect welds in assemblies that are too large for conventional chemical treatment lines. Welded joints are particularly prone to corrosion and even welds produced by solid-state processes, like friction stir welding (FSW), are highly susceptible to attack [3-5]. One possible technique, that has the potential to be applied locally over weld lines, alone, or as a base layer for subsequent chemical treatment, is pulsed laser surface melting (PLSM).

\footnotetext{
* Corresponding author. Tel.: +44 161306 3610; fax: +44 1613063586. E-mail addresses: paul_ryan@Praxair.com (P. Ryan), philip.prangnell@manchester.ac.uk (P.B. Prangnell).

${ }^{1}$ Now at Praxair Surface Technologies Ltd., Drakes Way, Swindon, Wiltshire SN3 3HX, UK.
}

At face value, high power density, short pulse length laser treatments, such as those that can be readily generated from excimer lasers, could be considered to be an ideal tool for surface chemical homogenisation and microstructural refinement. If the correct treatment parameters are chosen, the laser can be used to melt a region at the surface only a few microns thick [6-8]. The comparatively massive un-melted substrate will then act as a heat sink drawing energy rapidly from the liquid layer giving extremely high cooling rates $\left(10^{8}\right.$ to $\left.10^{10} \mathrm{~K} \mathrm{~s}^{-1}[6,7]\right)$. This will result in a solidification front that advances at a rate of several meters per second, which could potentially be controlled to be near, or above, the critical velocity for "absolute stability", at which point the high Péclet number cellular-planar transition occurs [9]. In this regime, much reduced solute redistribution will occur and, at sufficiently high solidification rates, the velocity dependent distribution coefficient will approach one and the solid that forms will exhibit no segregation and have the same composition as the liquid [10]. Whilst the laser melted region is in the liquid state, the solute originally contained in second phase particles will be redistributed by both fluid flow and diffusive processes. With sufficiently repeated pulses, chemical homogenisation would then be expected to occur, with the 
solute being retained in a uniform extended solid-solution during the rapid self-quench.

Recently, several studies have been reported demonstrating dramatic improvements in corrosion performance that can be gained from pulsed laser surface treatments of aluminium alloys and welds made in aerospace materials [3,5-8,11-15]. In all of these publications emphasis has been placed upon characterisation of the treated surfaces improved corrosion behaviour, with less attention paid to the microstructural changes in the subsurface layer that underpin these changes. The increase in the corrosion performance of pulsed laser treated alloys has been widely attributed to the formation of a surface layer that is much more chemically homogenous than the bulk material $[6,8,13,14]$, particularly over welds $[3,12]$. It has generally been assumed that the laser treatment removes second phase particles and partitionless re-solidification of the layer occurs [3,6,8,12-14]. Although SEM, optical imaging and limited transmission electron microscopy have been used to look at PLSM treated surfaces in cross-section, little evidence has been presented relating to the precise degree of homogenisation, or substructure of the layers. Unfortunately, most imaging is of too low a resolution to provide detailed information about structure within the PLSM layer, and TEM images published to date have concentrated on extremely small areas $[8,13-15]$ giving no real insight into variations that may occur through the layer thickness, or near to high solute concentrations that may result from melted constituent particles. Several authors have published low resolution images showing that PLSM had removed coarse constituent particles and precipitates formed during ageing at grain boundaries in the substrate $[7,8,14,15]$. However, Chan et al. has noted stringers of particles terminating at the base of PLSM layers on AA6013 and AA7075 $[7,8]$.

In light of the above omissions, this paper aims to provide a more detailed discussion of the typical microstructural features of pulsed laser surface treated layers that are formed by rapid repeated re-solidification of typical Al-aerospace alloys, including when they are applied over friction stir welded joints. Emphasis is placed upon the degree of chemical homogenisation and the grain and substructure formed in the re-solidified layers, as a function of the alloy substrate microstructure and layer thickness. The majority of this work was carried out using a pulsed excimer laser. However, work using other pulsed heat sources, selected to extend the range of solidification conditions that could be achieved, will also be referred to.

\section{Experimental details}

\subsection{Materials and laser processing}

Two typical aluminium aerospace alloys were initially used in this investigation, 2024-T3 and 7150-T6, in $4 \mathrm{~mm}$ thick plate. In addition, the 2024 material was also studied after friction stir welding using $770 \mathrm{rpm}$ and a travel speed of $195 \mathrm{~mm} / \mathrm{s}$, with a $16 \mathrm{~mm}$ diameter shoulder, threaded pin, tool. For reasons that will become apparent, the grain structures formed in the resolidified PLSM layers, with the Zr free 2024 and $\mathrm{Zr}$ containing 7150 alloys, were also compared to a $\mathrm{Zr}$ containing $2 \mathrm{xxx}$ alloy,
2096-T3, and a Zr free alloy 7xxx alloy, 7075-T6. In preparation for PLSM, a small amount of material $(0.1 \mathrm{~mm})$ was machined from the surfaces of all the samples to remove any oxide. This was followed by thorough cleaning with methanol.

All of the detailed microstructural analysis presented was performed after PLSM using a Lambda Physik LP315i excimer laser, operating at a wavelength of $308 \mathrm{~nm}$ (active medium $\mathrm{XeCl}$ ) and with a pulse length of $25 \mathrm{~ns}$, at BAE SYSTEMS Filton, UK. The laser beam was focused to a square $(1.3 \mathrm{~mm} \times 1.3 \mathrm{~mm}) \mathrm{spot}$ using a microlens array, providing a fluence of $10 \mathrm{~J} \mathrm{~cm}^{-2}$. It was then scanned across the surface with a standard raster pattern that subjected each point on the surface to nine overlapping pulses of radiation. This pulse density was adopted as parallel work had shown that it was the minimum required to give optimum corrosion performance [16,17]. A pulse repetition rate of $100 \mathrm{~Hz}$ was selected to ensure that the thermal cycle resulting from each pulse was an isolated event. All treatments were carried out in air. Further samples were produced with an Nd:YAG laser, a Qswitched $\mathrm{CO}_{2}$ laser, and an experimental pulsed electron beam system [17]. This was carried out to obtain a range of energy densities and establish the maximum melted layer thickness that could be achieved with the majority of the layer re-solidifying at a high enough velocity to achieve a stable growth front. Due to the thin geometry of the melted layer and the fact that the top surface is at its boiling point in all cases, the solidification time following a pulse is dominated by the rate of heat removal from the molten layer. It was thus not essential to have a constant pulse duration, incident radiation wavelength, or know the exact power density delivered into the material, for this particular aspect of the study.

\subsection{Microstructural characterisation}

Microstructural characterisation was performed using optical microscopy, a high resolution Philips XL30 FEGSEM, equipped with an HKL technology electron backscattered diffraction (EBSD) and an FEI Tecnai F30 FEGTEM. Cross-sectional specimens were cut perpendicular to the raster tracks for analysis using SEM and EBSD. They were prepared by mounting in a hard, edge retaining resin and polishing to a mirror-like finish, with a gentle final polish to improve EBSD indexing. For general TEM and STEM investigation, cross-sectional samples were cut using thin slices, from a sandwich of two surfaces glued face-toface, ground to $\sim 80 \mu \mathrm{m}$ thick, and finished using a precision ion polishing system. Site-specific TEM samples were also created using the "trench method" in an FEI Nova Lab 600 dual beam FIB (see [18] for details).

\section{Results and discussion}

\subsection{Surface appearance}

An example of the surface appearance after PLSM treatment under the standard conditions adopted is shown in Fig. 1. The pulsed scanned raster treatment has created a pattern of regular tracks of re-solidified material. At a higher magnification (Fig. 1b) a rippled morphology can be seen as a result of fluid 

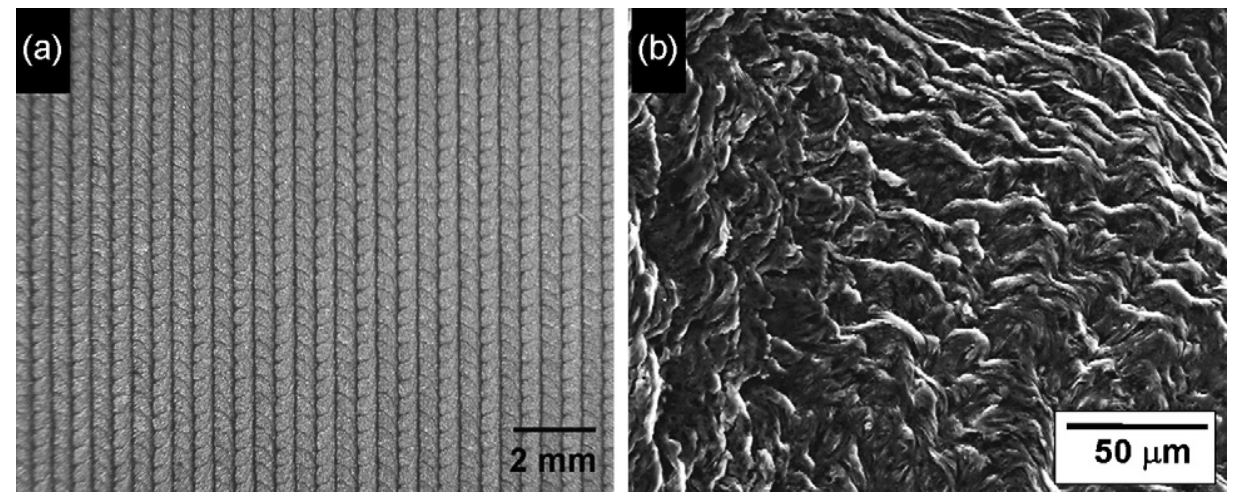

Fig. 1. Optical (a) and SEM images (b) of the surface of the excimer treated 2024 material under standard conditions.

flow away from the point of application of the laser beam, due to vaporisation at the surface associated with plasma formation and the recoil pressure of evaporation [19]. Because of the very high freezing rates, the material has solidified as it flows, freezing in the rippled morphology, which results in a non-uniform layer thickness. Although there is considerable lateral fluid flow, other work has shown that the surface roughness is no worse than the conventional machined finish found on aerospace parts [16].

\subsection{Overview of the PLSM layer substructure}

Fig. 2 shows typical cross-sectional FEGSEM images from the PLSM treated 2024-T3 and 7150-T6 materials. Due to the lateral fluid flow, the layers have a wave like surface appearance (Fig. 2a), corresponding to the ripples seen in Fig. 1, and there is evidence of some trapped porosity. Viewed in the FEGSEM, with back-scattered electron (BSE) imaging, there is no obvious evidence of a cellular structure and when viewed at this magni-
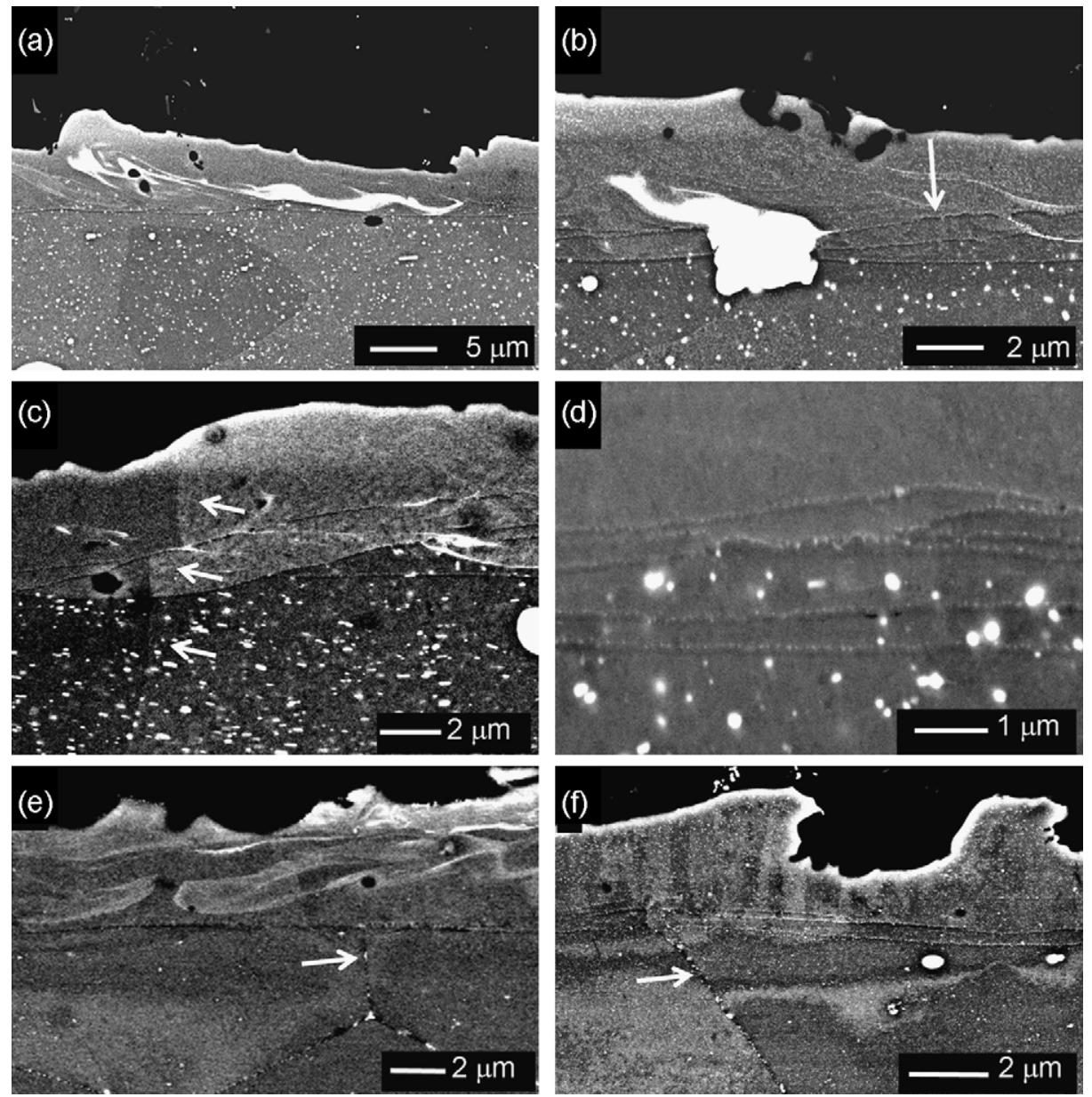

Fig. 2. Cross-section FEGSEM BSE images showing examples of the typical features of the PLSM layers formed over the 2024-T3 sheet (a)-(d) and the 7150-T6 material (e) and (f). In (d) the bands seen near the base of the layer are magnified. Areas highlighted by arrows are referred to in the text. 
fication the layer appears to have re-solidified with a sufficient velocity to obtain a stable growth front. In each case the base of the layer is associated with a thin light band of particles, indicating a concentration of high atomic number elements (arrows in Fig. 2b). There are other similar bands within the layer, which can be convoluted, but generally run roughly parallel to the plate surface. However, they tend to be more obvious near the base of the layer (magnified in Fig. 2d). From image analysis, it was found that the standard laser parameters resulted in the same average surface melted layer depth of $4.72 \pm 1.15 \mu \mathrm{m}$ for 2024 and $4.72 \pm 0.99 \mu \mathrm{m}$ for the 7150 alloy.

In the top $50 \%$ of the layers no large constituent particles could be found, but solute trails from particles that had melted to form a solute rich liquid, which had not fully dispersed, were readily seen from the Z-contrast (e.g. Fig. 2a). The solute trails give evidence of considerable lateral fluid flow, resulting from the aggressive nature of the laser pulses on the surface, but even nine overlapping repeated pulses have been insufficient to fully disperse the solute rich liquid. In the bottom half of the layer partially melted constituent particles were seen (e.g. Fig. 2b), again exhibiting solute rich trails. These trails contained high concentrations of alloying elements. For example in the 2024 alloy local $\mathrm{Cu}$ contents of up to $15 \%$ were measured by EDX (see Fig. 11b).

In the 2024 alloy the $\mathrm{Al}_{20} \mathrm{Cu}_{2} \mathrm{Mn}_{3}$ dispersoid particles present throughout the substrate were completely removed from the uppermost $90 \%$ of the layer thickness. However, just above the layer's base some had either survived in the melt (Fig. 2d), or melted leaving their solute trails still visible. The smaller $\mathrm{Al}_{3} \mathrm{Zr}$ dispersoids present in the 7150 alloy were not readily resolvable in the layer using SEM imaging. In the T6 condition the 7150 alloy substrate contained heterogeneously nucleated $\eta\left(\mathrm{MgZn}_{2}\right)$ along its grain boundaries (Arrow in Fig. 2e and f). The laser surface melting treatment was found to have completely dispersed these precipitates, as can be seen from Fig. $2 \mathrm{f}$.

By studying samples with different numbers of repeated overlapping pulses, it was found that there was a direct correlation between the pulse density and the number of thin lateral bands observed in a melted layer, as can be seen from Fig. 3. It was also noted that the solute distribution in the layers improved with

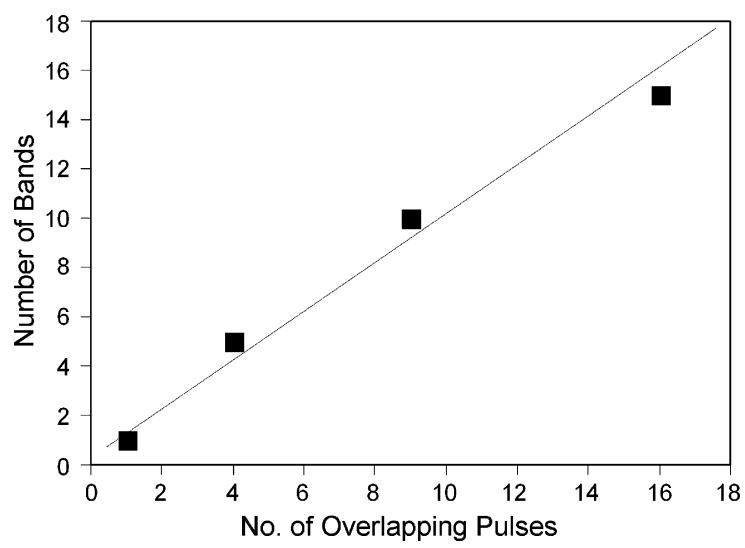

Fig. 3. Correlation between different densities of repeated overlapping laser pulses and the number of thin lateral bands observed in a PSLM layer.
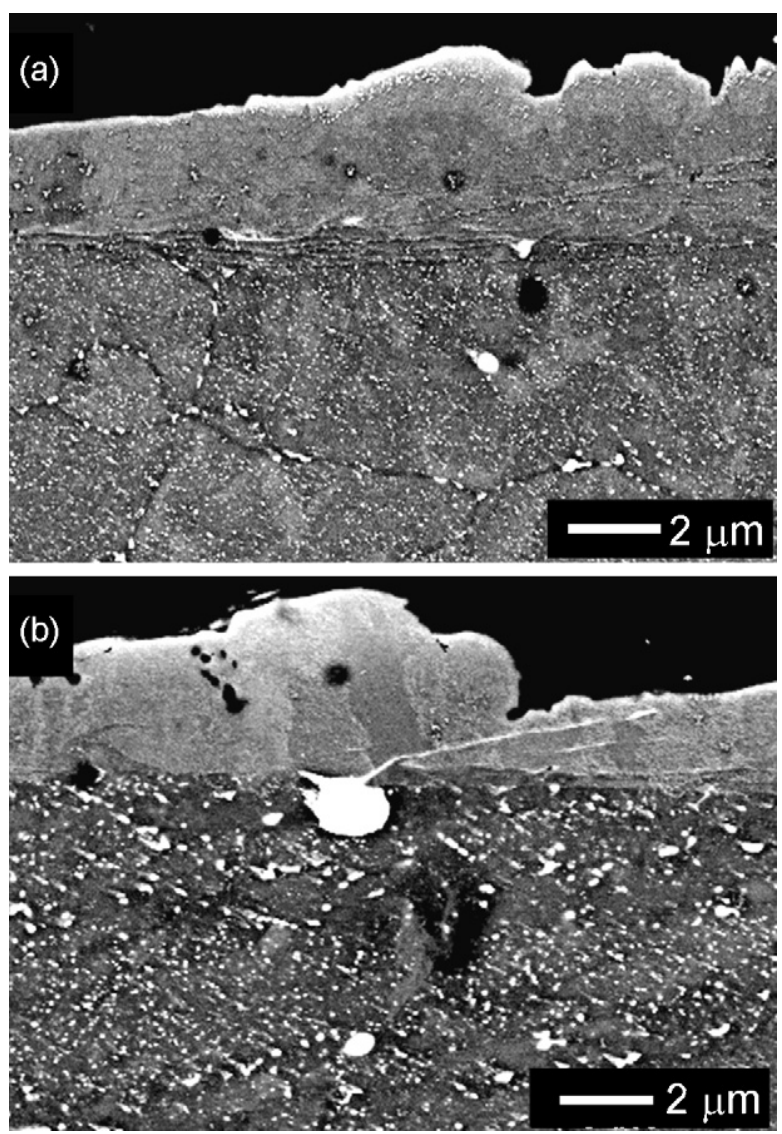

Fig. 4. Cross-section FEGSEM BSE images showing examples of the PLSM layer formed over a friction stir weld in the 2024 material (a) above the TMAZ-HAZ boundary and (b) the weld centre, or nugget region.

the number of repeated pulses, but the layer quality deteriorated (level of porosity and uniformity), leading to little significant improvement in corrosion performance for greater than nine overlapping pulses [17].

In the backscattered images in the 2024 alloy, from the channelling contrast, there is evidence of the substrate grain boundaries continuing upwards through the re-solidified layer (arrowed in Fig. 2c), and being stepped when they intersect the lateral bands, where the material has been re-melted by an overlapping subsequent pulse. In contrast, in the case of the 7150 material, the BSE contrast is indicative of many fine columnar grains growing up from the substrate with no correlation to the substrate grain structure (Fig. 2e).

No obvious difference was observed in the layer appearance, with respect to the distribution of second phase particles and solute, when studied over the heat affected and thermomechnically affected zones of 2024 FSWs (Fig. 4), confirming that the PLSM treatment produces a chemically more uniform layer over weld regions. The constituent particles present in the heavily strained nugget region can be more dispersed by the welding process, under certain welding conditions [20] and this might be expected to locally effect the distribution of solute trails in some treated welds. The coarse $S$ precipitates formed by overageing [21] in the HAZ and TMAZ, were fully dissolved and appeared to have no influence on the layer homogeneity. In comparison, 


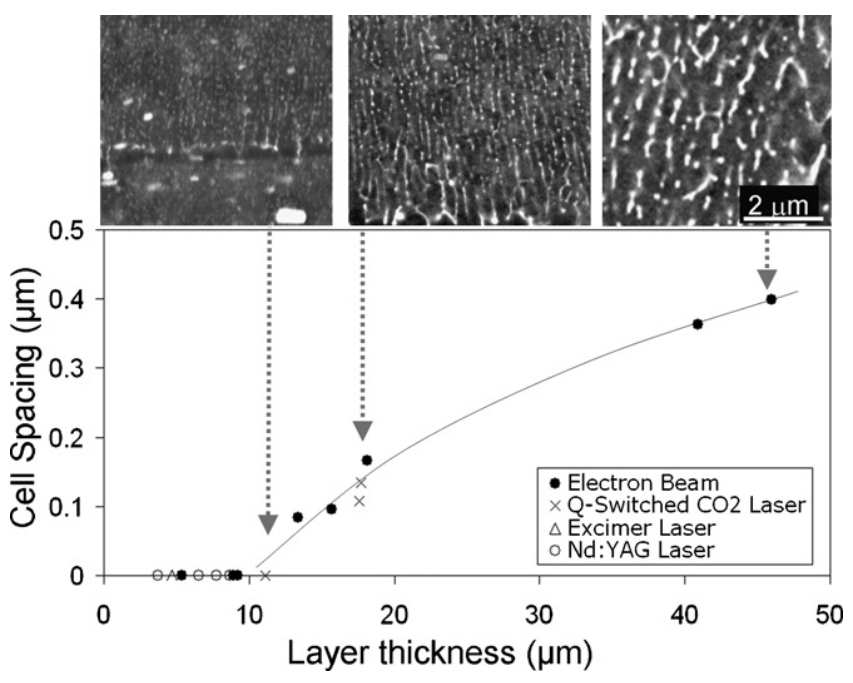

Fig. 5. Variation in cell spacing with melt depth for 2024-T3 using a variety of pulsed treatment methods. The inserted images show corresponding typical microstructures.

the modified substrate grain structure in the nugget zone had a substantial effect on the PLSM layer matrix re-growth behaviour, as will be discussed further below.

\subsection{Solidification conditions}

It was found that the standard laser parameters gave the same average melt depth of $\sim 5 \mu \mathrm{m}$ for the 2024 and 7150 alloys. With this melt depth initial inspection by SEM gave the impression of partitionless solidification (e.g. Fig. 2). While results from this standard condition are discussed in more detail below, a much wider range of melt depths than were possible with the pulsed excimer laser were obtained using Nd:YAG and Q-switched $\mathrm{CO}_{2}$ lasers and an experimental pulsed electron beam system. Data from these samples is shown in Fig. 5, where the melt depth is plotted against average cell spacing over a range of liquid thickness up to approximately $40 \mu \mathrm{m}$. Despite the range of techniques employed, all the data fits on one curve confirming that the freezing rate is dominated by the rate of heat removal from the molten layer after the incident pulse has finished. This is due to the thin geometry relative to the spot size, and the similar boundary conditions in each case; i.e. the top surface is at its boiling point and the bottom at the alloys melting point. Two regimes can also be seen; below $\sim 10 \mu \mathrm{m}$ in thickness, where the majority of the layer appears to have frozen partitionlessly, and above $10 \mu \mathrm{m}$, where cellular structures are seen. In the second regime the layer solidified with a fine cellular structure, growing upwards-parallel to the thermal gradient, which coarsens with the layer thickness. To date, layers below this thickness have been reported as being 'homogeneous', which has been linked to a substantial improvement in corrosion resistance [3,5-8,11-15]. To prevent the formation of a cellular structure throughout the layer on resolidification, and ensure a reasonable chance of obtaining a chemically homogeneous layer, the melt depth is thus restricted to less than $\sim 10 \mu \mathrm{m}$ in thickness. It should be noted that this may cause problems with some subsequent conversion treatments that can remove several microns of material [1]. The standard excimer conditions produced a layer thickness well within this 'stable' growth front range $(\sim 5 \mu \mathrm{m})$ and were thus used for more detailed analysis.

A standard analytical model has been used to estimate the freezing time, cooling rate and solidification velocity [22] during pulsed laser surface treatment. The model is based upon a solution to the heat diffusion equation that assumes a planar, one-dimensional, heat wave propagates into the sample perpendicular to the surface. For a large spot size $(1.3 \mathrm{~mm})$ relative to the melt depth $(\sim 5 \mu \mathrm{m})$ this is a reasonable assumption. The cooling stage of the model is given by

$$
\begin{aligned}
T_{(z, t)=} & \frac{2 A I_{0} \kappa^{1 / 2}}{k_{\mathrm{T}}}\left[t^{1 / 2} \mathrm{i} \operatorname{erfc}\left(\frac{z}{2\left(\kappa_{t}\right)^{1 / 2}}\right)\right. \\
& \left.-\left(t-\tau_{\mathrm{p}}\right)^{1 / 2} \mathrm{i} \operatorname{erfc}\left(\frac{z}{2\left[\kappa\left(t-\tau_{\mathrm{p}}\right)\right]^{1 / 2}}\right)\right]
\end{aligned}
$$

where $T_{(z, t)}$ is the temperature as a function of depth $z$, and time $t$, is the radiation adsorpitivity, $I_{0}$ the irradiance, $k_{\mathrm{T}}$ thermal conductivity, $\kappa_{\mathrm{T}}$ thermal diffusivity, and $\tau_{\mathrm{p}}$ is the pulse length (full details can be found in [22]). The model does not consider latent heat evolution and assumes that the thermo-physical properties are independent of temperature. In this case values for the solid alloys were used, averaged over the temperature range.

Although the adsorptivity is not accurately known, the model could be calibrated based on the melt depth by assuming that top surface reached the materials boiling point $\left(T_{\mathrm{bp}}\right)$ and the layer bottom corresponded to the materials melting point $\left(T_{\mathrm{mp}}\right)$, or liquidus temperature. If material above the boiling point is removed, the average cooling rate is then given by the ratio of ( $T_{\mathrm{bp}}-T_{\mathrm{mp}}$ ) to the solidification time and the velocity of the growth front could be obtained by tracking the melting point isotherm. Using this model, the average cooling rate for the standard excimer treated $\sim 5 \mu \mathrm{m}$ thick layers was estimated to be $5.2 \times 10^{9}$ and $4.7 \times 10^{9} \mathrm{~K} \mathrm{~s}^{-1}$ and the average growth front velocity $\sim 12$ and $11 \mathrm{~m} \mathrm{~s}^{-1}$ for the 2024 and 7150 alloys, respectively.

The front velocity for absolute stability, $V_{\mathrm{A}}$, for a dilute alloy is given by

$V_{\mathrm{A}}=\frac{\Delta T_{0} D}{k_{\mathrm{v}} \Gamma}$

where $\Delta T_{0}$ is the liquidus-solidus range at $C_{0}, D$ the diffusion coefficient of solute in the liquid, $k_{\mathrm{v}}$ the non-equilibrium partition coefficient and $\Gamma$ is the Gibbs-Thomson coefficient $[9,10]$. The value of $k_{\mathrm{v}}$ is velocity dependent, varying between the equilibrium constant and 1 . The minimum melt thickness, where interface instability was first observed throughout the layer in the 2024 material, was $\sim 10 \mu \mathrm{m}$ (Fig. 2), which corresponds to an average solidification front velocity of $\sim 5 \mathrm{~m} \mathrm{~s}^{-1}$. This value agrees well with the lower limit of $V_{\mathrm{A}}$ for absolute stability in an $\mathrm{Al}-4.5 \mathrm{Cu}$ binary alloy (with a similar $\mathrm{Cu}$ content to 2024), which was estimated from Eq. (2) to be $5.4 \mathrm{~m} \mathrm{~s}^{-1}$ (assuming $\Delta T_{0}=72 \mathrm{~K}, k_{\mathrm{v}}=k=0.17, D=3.0 \times 10^{-9} \mathrm{~m}^{2} \mathrm{~s}^{-1}$ and $\left.\Gamma=2.4 \times 10^{-7} \mathrm{~m} \mathrm{~K}[10]\right)$. 


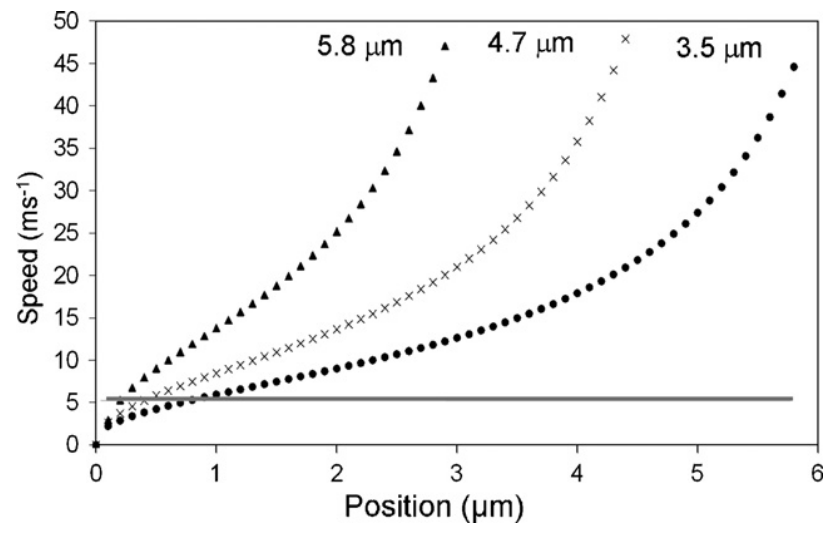

Fig. 6. Solidification front velocity predicted for the 2024-T3 material as a function of position during re-solidifcation of the laser melted surface layer, for three melt depths, corresponding to the average, and upper and lower limits of the layer thickness, observed under standard treatment conditions. The vertical line corresponds to the estimated limit of absolute stability.

As well as considering the average freezing parameters, it is useful to plot the solid-liquid growth velocity as a function of distance, during re-solidification of the liquid layer following a single laser pulse, predicted by Eq. (1). This function is shown in Fig. 6 for three different melt depths. The vertical line corresponds to $V_{\mathrm{a}}$, the estimated limit for absolute stability. The model shows that there is an initial transient where the growth front accelerates rapidly from zero to an approximately linearly increasing velocity, and then accelerates again at an increasing rate near the end of solidification. Even for the thinnest liquid layer shown, the initial transient growth rate thus falls below that of the limit of absolute stability, which is reached after an increasing proportion of the layer depth as the cooling rate decreases with greater layer thicknesses.

\subsection{PLSM layer grain structure}

The grain structure within the re-solidified layers was studied further by cross-sectional EBSD mapping, shown in Fig. 7. It should be noted that it is very difficult to obtain high uniform levels of indexing when applying the EBSD technique to sectioned surfaces and only a small degree of cleaning was applied to the data to avoid reconstruction errors in the maps. Unindexed areas have, therefore, been left black. Nevertheless, the grain structure in the melted layer on the 2024 plate (Fig. 7a) can be clearly seen to have re-grown epitaxially upwards towards the surface, mimicking the substrate in terms of both the grain orientation and size. This is a well-known phenomenon, which is commonly found during re-solidification of a partially melted alloy in a positive liquid thermal gradient, and occurs because there is a negligeable energy barrier for heterogeneous nucleation when the liquid and substrate are the same material [23]. The same
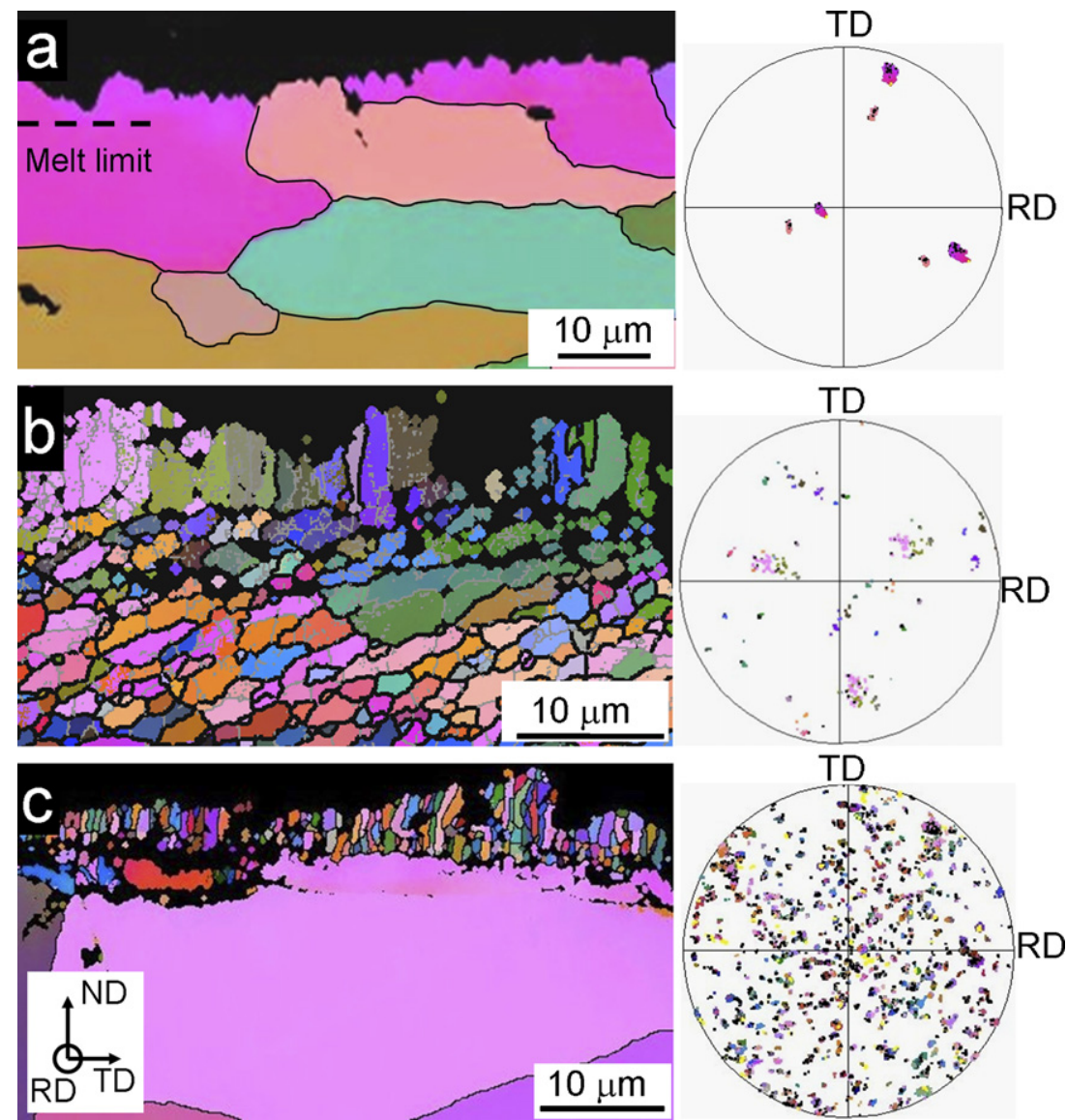

Fig. 7. EBSD maps showing the grain structures in the PLSM re-solidified layers formed over (a) the 2024 parent material; (b) 2024 FSW nugget zone and (c) the 7150, Zr containing alloy, parent plate. The corresponding 100 pole figures are taken from the re-solidified layer only. 
effect was also observed for the PLSM layer that re-solidified over a 2024 friction stir weld zone, where the grain structure again re-grew epitaxially from the substrate.

Fig. $7 \mathrm{~b}$ shows that the grain size in the nugget zone substrate is an order of magnitude lower than seen in the parent material, due to the ultra high strain and thermal cycle experienced during joining, which results in dynamic recrystallisation [24]. Because the substrate grain size is now smaller than the melt layer thickness, columnar grains develop in the PLSM layer, nucleated from the nugget grains, and grow upwards through the layer following the thermal gradient. Their orientation and width is determined by the nugget grains, even to the extent of continuing low angle boundaries within the nugget grains, as the solid front grows, indicating that the PLSM layer forms epitaxially with the substrate.

The right hand grain over the parent 2024 substrate in Fig. 7a is orientated with ND close to a $\langle 001\rangle$ direction and has overgrown its left neighbour. However, this is probably not a common effect as the pole figure in Fig. 7c, shows that when there is sufficient statistical data no strong preferred texture was formed during re-growth of the layer, which is probably because it is too thin for competitive growth to become established.

In comparison to the 2024 alloy, the grain structure seen within the PLSM layer on the 7150 parent plate is strikingly different. In Fig. 7c, despite the coarse substrate grain size the PLSM layer can be seen to be comprised of miniature, $\sim 300-500 \mathrm{~nm}$ wide, columnar grains that have no relation, in terms of their orientation, to the substrate. A possible explanation for this difference is that $\mathrm{Al}_{3} \mathrm{Zr}$ dispersoid particles present in the 7150 alloy can act as heterogeneous nucleants for $\alpha$-Al. In their metastable form, these particles have an $\mathrm{L}_{2}$ FCC crystal structure with a lattice parameter very close to that of aluminium and in rapid solidification conditions are known to act as grain nucleants [25]. With a rapid pulsed laser treatment, due to their high melting point [26], some of these particles could have survived in the melt at the base of the LSM layer where they may
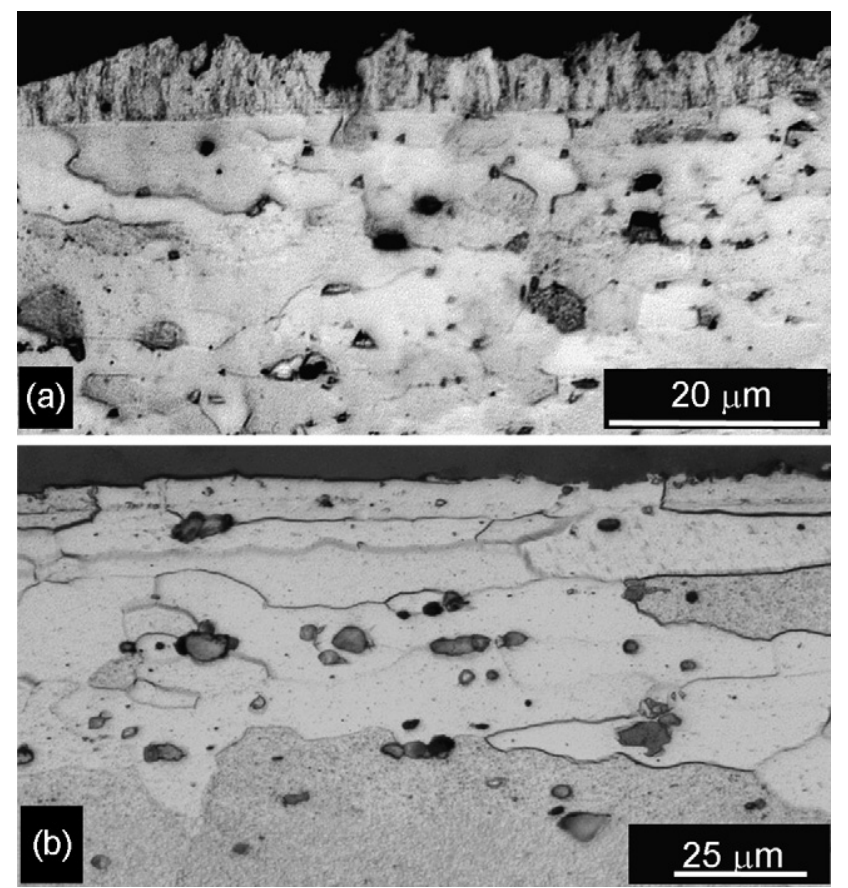

Fig. 8. Optical images from sections through the PLSM treated layers formed over a (a) 2096 ( $\mathrm{Zr}$ containing) and (b) 7075 ( $\mathrm{Zr}$ free) alloys, showing the layer grain structure.

have acted as efficient nucleants for $\alpha$-Al grains. Similar observations, of the formation of a narrow band of fine non-dendritic equiaxed grains, have been reported at the fusion boundary in certain fusion welded $\mathrm{Zr}$ and $\mathrm{Li}$ containing aluminium alloys. This behaviour has been claimed to occur via heterogeneous nucleation on $\mathrm{Al}_{3}\left(\mathrm{Li}_{x}, \mathrm{Zr}_{(1-x)}\right)$ dispersoid particles [27,28].

To gain support for this hypothesis, a comparable $\mathrm{Zr}$ free $7 \mathrm{xxx}$ series alloy, 7075-T6, and a $\mathrm{Zr} / \mathrm{Li}$ containing 2xxx series alloy, 2096-T3, were also examined after PLSM treatment (Fig. 8). The images of these two materials show the opposite behaviour,
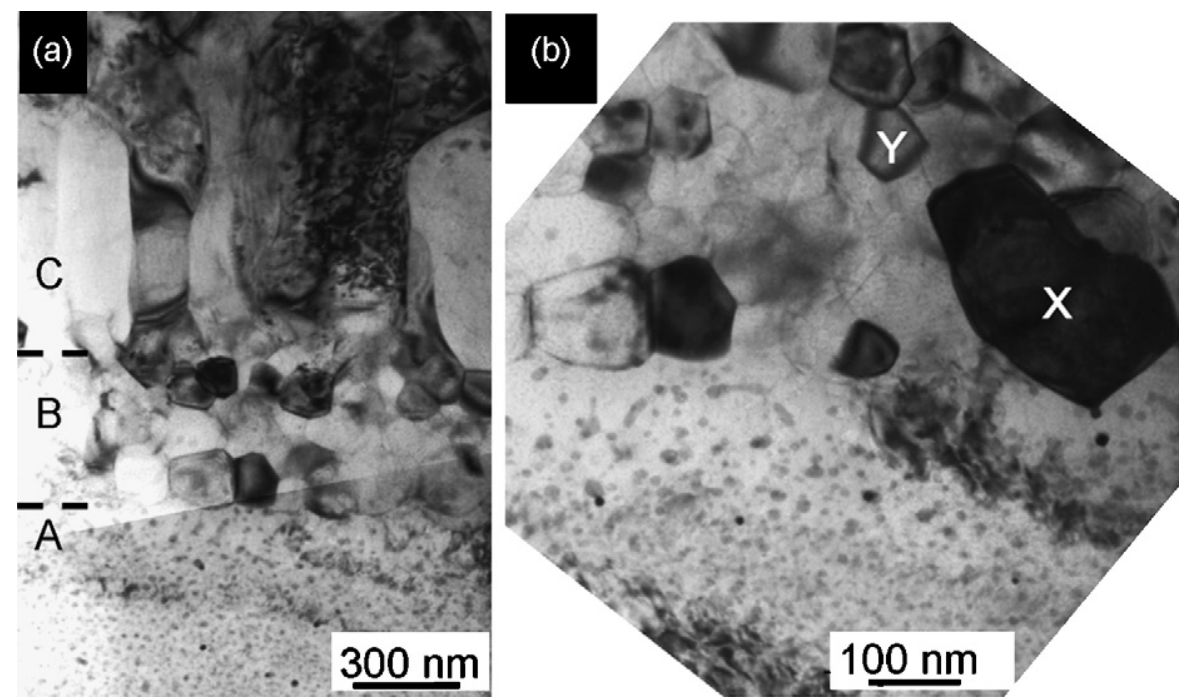

Fig. 9. Cross-sectional TEM images through the base of the PLSM layer formed over the 7150 alloy: (a) showing the grain structures at the bottom of the layer, with region $\mathrm{B}$ magnified in (b). 

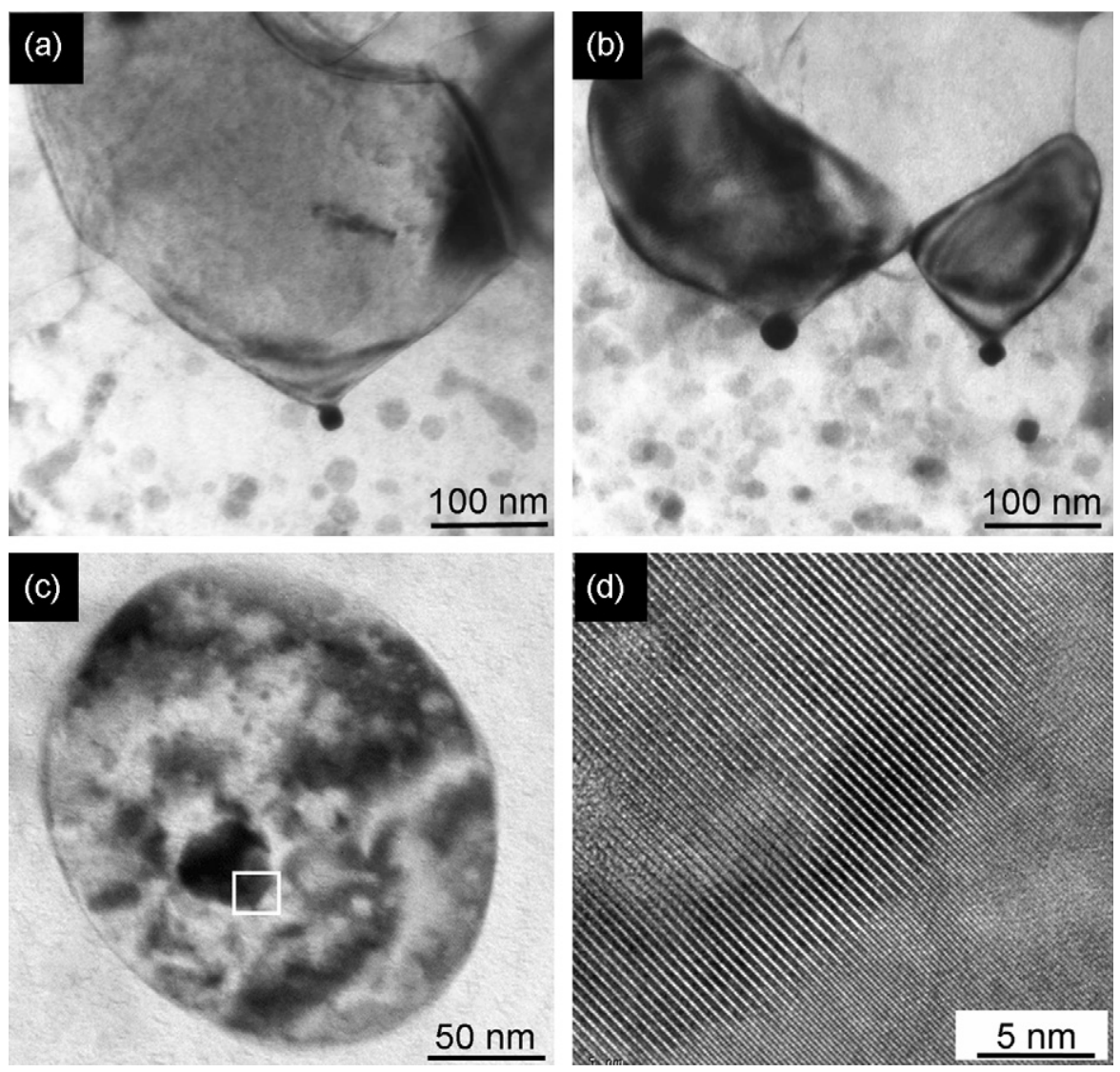

Fig. 10. Type ' $\mathrm{X}$ ' seed grains that have nucleated from $\beta^{\prime} \mathrm{Al}_{3} \mathrm{Zr}$ particles at the melt base (a) and (b). (b) An example of a type ' $\mathrm{Y}$ ' seed grain that is equiaxed in shape and has nucleated from $\mathrm{Al}_{3} \mathrm{Zr}$ dispersoids in the melt ahead of the growth front. In (d) a lattice image is shown of epitaxial matching across the $\beta^{\prime} / \alpha-\mathrm{Al}$ interface, from the highlighted are in (c).

relative to the $2 \mathrm{xxx}$ series 2024 and $7 \mathrm{xxx}$ series 7150 alloys previously investigated. A fine columnar grain structure has now formed over the 2096 alloy which contains $\mathrm{Zr}$ (Fig. 8a), but not over the $\mathrm{Zr}$ free 7075 alloy (Fig. 8b).

The ultra-fine columnar grained PLSM layer formed over the 7150 alloy was examined further in the TEM. Fig. 9a gives an overview of the base of the layer. Three distinct regions can be identified (A-C in Fig. 9a). Firstly, there is a region of tiny 100-300 nm equiaxed grains, referred to here as "seed grains" (region B). From certain seed grains, columnar grains (region A) have then grown preferentially towards the free surface parallel to the maximum thermal gradient. Below these two regions is the coarse grained parent material (region C). In Fig. 9b two different morphologies of seed grain can be seen. The first, labelled ' $\mathrm{X}$ ', appears to have nucleated from particles that were extremely close to the bottom of the melt layer. A second type, labelled $\mathrm{Y}$, is equiaxed in shape and has nucleated further ahead of the growth front.

Higher magnification TEM imaging, EDX, and diffraction analysis, revealed the presence of $\beta^{\prime} \mathrm{Al}_{3} \mathrm{Zr}$ particles acting as grain nucleants for the seed grains in layer B. Fig. 10a and $b$ shows two type ' $\mathrm{X}$ ' seed grains and the particles they have grown from, with which they are coherent. A type ' $Y$ ' seed grain is shown in Fig. 10c, which is approximately $200 \mathrm{~nm}$ in diameter and has an $\mathrm{Al}_{3} \mathrm{Zr}$ particle present at its centre. Lattice imag- ing in Fig. 10d demonstrates that the $\mathrm{Al}_{3} \mathrm{Zr}$ particle and $\alpha-\mathrm{Al}$ matrix have a cube-cube relationship. The nucleation of such an equiaxed grain ahead of the growth front would require a small undercooling in the liquid. Given the fact that the growth front must first accelerate to the velocity of absolute stability (Fig. 6), a small region of constitutional undercooling is possible during the early stages of re-growth (as will be seen below). However, a contributing factor may be that when the $\mathrm{Al}_{3} \mathrm{Zr}$ dispersoids are partially melted this creates a $\mathrm{Zr}$ rich liquid shell around the particles, which does not have time to disperse, and locally raises the liquidus melting point.

\subsection{PLSM layer banding and segregation}

It was demonstrated above (Fig. 3) that there is a correlation between the pulse density and the number of thin lateral solute rich bands seen in the BSE SEM images in Fig. 2. From the position of the bottom band in Fig. $2 \mathrm{a}$, it is apparent that the lateral bands occur close to the depth from where the material melted by an individual rastered pulse begins to re-grow. To gain more detailed information about the identity of their structure, the bands were examined further using a combination of HAADF STEM imaging and EDX analysis. Fig. 11b shows an image from the first band, seen at the base of the PLSM layer in 2024. Z-contrast reveals that the banded structure at the bottom 

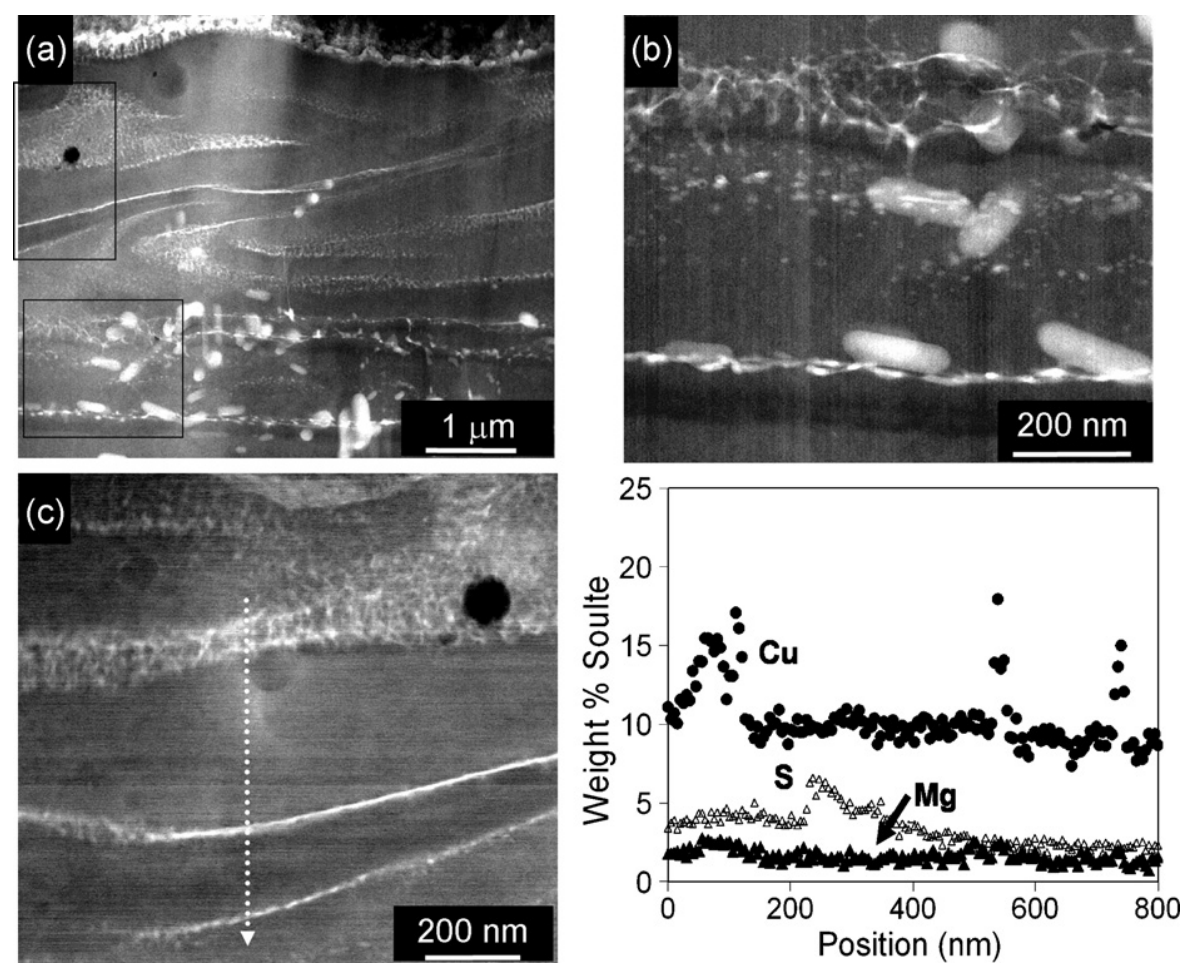

Fig. 11. HAADF STEM images taken from cross-sections through the PLSM processed 2024 alloy: (a) a general view of the laser melted region; (b) thin lateral bands at the base of the layer which contain surviving $\mathrm{Al}_{20} \mathrm{Cu}_{2} \mathrm{Mn}_{3}$ dispersoid particles, and (c) the structure of the solute rich trails. In (c) a vertical EDX line scan through the lateral solute rich bands is also shown (along arrowed line).

of the image is the result of segregation of solute ahead of the growth front, forming a second phase as a string of discontinuous particles. The EDX line scan indicates that the particles in the band have a higher $\mathrm{Cu}$ and $\mathrm{Mg}$ content than the surrounding matrix. Although metastable phases can be observed under rapid solidification conditions [29] and the crystal structure of the particles observed has not yet been determined, these particles are probably the $\mathrm{S}$ phase. The high density of second phase particles in such narrow bands might be expected to cause inservice problems, like rapid lateral corrosion and delimitation of the laser treated layer if it is penetrated during service.

The modelling results presented in Fig. 6 show that there is an initial transient period where, on re-solidification following each pulse, the growth front is rapidly accelerating. The growth front travels at velocities in excess of $V_{\mathrm{a}}\left(\sim 5 \mathrm{~ms}^{-1}\right)$ after a distance of only $\sim 500 \mathrm{~nm}$, whereupon it appears to obtain stability. There will thus be a narrow initial region of growth at start of re-solidification of each pulse where the front can become morphologically unstable, resulting in the formation of fine scale perturbations and solute segregation. Oscillatory instabilities, or banded structures, can also occur in the transition form cellular to planar front growth which occurs in the range of $1-5 \mathrm{~m} \mathrm{~s}^{-1}$ in dilute $\mathrm{Al}-\mathrm{Cu}$ alloys and this may be responsible for the bands seen associated with growth acceleration [30].

When viewed at high magnifications (Fig. 11a), the bands can often appear variable in width and structure, due to sectioning effects if they are not vertical in the plane of the foil, and where they become enriched by interacting with solute rich trails developed by liquid flow from melted constituent particles
(Fig. 11a and c). The variable nature of the local solidification conditions and composition makes interpretation of these structures problematic. The solute enriched trails from melted constituent particles can be seen to be comprised of a complex, locally variable, extremely fine cellular, or eutectic, structure. This behaviour is difficult to disassociate from the effect of the transition in growth velocity caused by overlapping pulses, and an uneven layer thickness, but appears to be closely related to the large local increase in solute content that results in the trails from melted constituent particles. This can lead to large local differences in composition and melting point. For example, in 2024 average $\mathrm{Cu}$ levels in the solute trails were measured to be as great as $15 \%$ and they are also enriched in $\mathrm{Si}, \mathrm{Fe}$ and other elements. In rapid solidification differences in composition and growth velocity are known to alter the phases selected and growth morphology formed [28-31]. The ultimate stability criterion is also composition dependent. For example Kurz et al. have constructed solidification microstructure selection maps for $\mathrm{Al}-\mathrm{Cu}$ binary alloys and shown that there is a rise in the velocity required for ultimate stability from 2 to $5 \mathrm{~m} \mathrm{~s}^{-1}$ in the range $1-10 \mathrm{wt} \% \mathrm{Cu}[29,30]$.

\subsection{Redistribution of solute from second phase particles}

Previous studies into pulsed laser surface melting of aluminium have concluded that the improvements in corrosive properties are a result of homogenisation of the surface region $[6,8,13,14]$. Although better than the parent material, due to constituent particles being largely dispersed by the process, the 

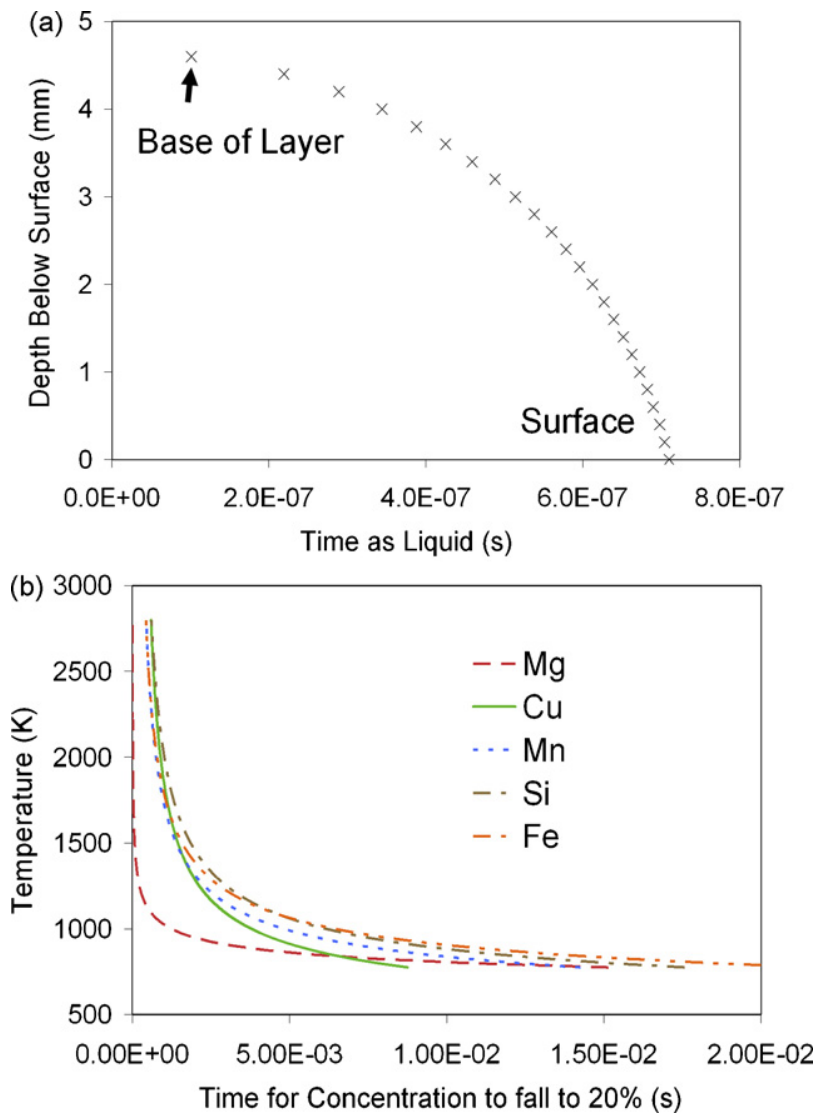

Fig. 12. (a) The estimated time spent liquid, plotted against position through the thickness of a $5 \mu \mathrm{m}$ thick melted layer, for a single laser pulse and (b) the time required for the composition at the centre of a melted constituent particle to fall to $20 \%$ of its initial level by diffusion in the liquid, as a function of temperature, for a constituent particle of the average size measured in the 2024 substrate material $(4.4 \mu \mathrm{m})$

images presented in Figs. 2, 4 and 11 indicate that the layer is far from homogeneous and contains solute rich trails, as well as the characteristic bands discussed above. The success of laser treatment relies on the aluminium matrix and second phase particles being taken into the liquid phase and mixed by a combination of stirring and diffusion to form a uniform liquid. Ideally, the liquid film should then re-solidify sufficiently quickly to prevent interface instability, trapping the solute in solid-solution. However, because of the short time spent in the liquid phase, it is extremely difficult to achieve a uniform solute distribution.

In Fig. 12a, the estimated time spent in the liquid phase after a single excimer laser pulse, as predicted by the model described in Section 3.5, is plotted against position through the thickness of a $5 \mu \mathrm{m}$ thick melted layer. The longest period the material is liquid is only $\sim 7 \times 10^{-7} \mathrm{~s}$. A simple model can be used to give a first order estimate of the time required for the solute rich liquid formed by a melted constituent particle to disperse by diffusion. The solution to Fick's second law for the decay in composition at the centre of a one-dimensional step function is given by

$C_{(0, t)}=\frac{1}{2}\left[\operatorname{erf}\left(\frac{h}{2 \sqrt{D t}}\right)-\operatorname{erf}\left(\frac{-h}{2 \sqrt{D t}}\right)\right]$ where $h$ is the initial half width and $D$ is the diffusing species diffusion coefficient [32]. Data for diffusion coefficients of elements in liquid aluminium have been reviewed by Du et al. [33]. These parameters have been used to estimate the time required for the composition at the centre of a melted constituent particle to fall to $20 \%$ its initial level, as a function of temperature, for a constituent particle of the average size measured in the 2024 substrate material $(4.4 \mu \mathrm{m})$, and are shown in Fig. 12b, where it is apparent that the time required is considerably longer than a single pulse duration. For example at the boiling point of aluminium it would require $\sim 800$ overlapping pulses to reduce the level of $\mathrm{Cu}$ to $20 \%$ of its original value by diffusion alone. Even though this is an upper bound estimate, because liquid shear will disperse the solute rich volumes created by particle melting, it is thus not surprising that enriched liquid trails are still present within the layers after nine overlapping pulses.

In laser surface treatment it is impractical to apply large numbers of pulses to a single location, as this would lead to an extremely slow process time when treating large areas of material. This will then impose a limit on the number of pulses and hence level of homogenisation that can be achieved. Furthermore, studies of samples treated with large numbers of pulses per unit area showed they can suffer from severe porosity [17] and this results in little significant improvement in corrosion performance over the nine overlapping pulses used in this study. The liquid shear that occurs is related to the violence of the plasma formation and degree of evaporation, which is controlled largely by the intensity of the laser pulse, but is also influenced by the atmosphere and incident wavelength. A high degree of liquid flow is desirable to improve mixing, but this will degrade the quality of the treated layer by increasing its roughness, variability in thickness, and porosity.

\section{Conclusions}

In the context of developing pulsed excimer laser melting for application in corrosion protection systems for welded joints, the effect of the treatment on the grain structure and chemical homogeneity of the surfaces of typical Al-aerospace alloys and friction stir welds, has been studied. Overall, a thin surface layer can be achieved that shows a higher level of homogeneity and refined microstructure, relative to the substrate material, particularly when applied to welds. Of particular benefit is the dispersal of coarse constituent particles and active second phase particles from the grain boundaries in the parent material. However, the layer is by no means as homogeneous as has previously been claimed and develops a grain structure that is very sensitive to that of the substrate and the presence of $\mathrm{Zr}$, an important dispersoid forming element in high strength aerospace alloys.

To prevent the formation of a segregated cellular structure throughout the layer, on re-solidification, the melt layer thickness is restricted to less than approximately $10 \mu \mathrm{m}$ thick, which may cause problems with some subsequent conversion treatments that can remove several microns of material. Below this thickness limit the majority of the layer reaches the solidification velocity required for ultimate stability and solidifies as 
single phase solid-solution, however, it still contains bands of fine second phase particles.

In the $\mathrm{Zr}$ free alloys investigated (2024 and 7075), upon solidification grains from the substrate re-grow epitaxially back up through the melted layer towards the surface. This creates a coarse grain structure that mimics that of the parent material, but fine columnar grains are formed over the highly refined FSW nugget zone grain structure. In $\mathrm{Zr}$ containing parent alloys, like 2096 and 7150, small grains nucleate heterogeneously on $\mathrm{L}_{2}$ $\mathrm{Al}_{3} \mathrm{Zr}$ dispersoid particles that survive ahead of the solid-liquid interface, resulting in an exceptionally fine columnar grain structure.

Due to the extremely short melt times the layer is not completely homogeneous. Even with considerable liquid shear, it is impossible to fully disperse solute from the melted constituent particles, which leaves solute rich trails through out the layer. Near the base of the layer second phase particles do not fully melt. The treated layers contain a series of cellular/eutectic bands that correlate to the number of pulses of radiation received. These bands are the result of an initial transient caused by the growth front accelerating through speeds below ultimate stability, combined with the solute enriched trails extending the interface stability criteria to greater growth velocities.

\section{Acknowledgements}

The authors would like to acknowledge Eirian Siggs and Stephen Morgan, of BAE Systems, for supplying the LSM samples, Dr. R.M. Langford for assistance with the FIB TEM sample preparation, Prof. S.W. Williams (Cranfield University) for many useful discussions on the physics of laser surface treatment, and Airbus UK and the EPSRC-University of Manchester Light Alloys Portfolio Partnership (EP/D029201/1) for financial support.

\section{References}

[1] G.W. Critchlow, K.A. Yendall, D. Bahrani, A. Quinn, F. Andrews, Int. J. Adhes. Adhes. 26 (2006) 419-453.

[2] B. Christener, J.M. Coury, S. Higgins, Proceedings of the Fourth International Friction Stir Welding Symposium, Park City UT, USA, 2003.
[3] A.J. Davenport, M. Jariyaboon, C. Padovani, N. Tareelap, B.J. Connolly, S.W. Williams, E. Siggs, Mater. Sci. Forum 519-521 (2006) 699-704.

[4] D. Allehaux, F. Marie, Mater. Sci. Forum 519-521 (2006) 11311138.

[5] A.J. Davenport, R. Ambat, M. Jariyaboon, P.C. Morgan, D. Price, A. Wescott, S.W. Williams, J. Corros. Sci. Eng. 6 (2004).

[6] M.L. Autric, J. Perrais, G. Barreau, Proc. SPIE 3888 (2000) 742-749.

[7] C.P. Chan, T.M. Yue, H.C. Man, Mater. Sci. Technol. 18 (2002) 575-580.

[8] C.P. Chan, T.M. Yue, H.C. Man, J. Mater. Sci 38 (2003) 2689-2702.

[9] R. Trivedi, W. Kurz, Acta Metall. 34 (1986) 1663-1670.

[10] W. Kurz, D.J. Fisher, Fundamentals of Solidification, Trans Tech Publications, 1992.

[11] A. Koutsomichalis, A. Kefalidou, J. Laser Appl. 8 (1996) 247-250.

[12] S.W. Williams, R. Ambat, D. Price, M. Jariyaboon, A.J. Davenport, A. Wescott, Mater. Sci. Forum 426-432 (2003) 2855-2860.

[13] T.M. Yue, C.F. Dong, L.J. Yan, H.C. Man, Mater. Lett. 58 (2004) 630-635.

[14] T.M. Yue, L.J. Yan, C.P. Chan, C.F. Dong, H.C. Man, G.K.H. Pang, Surf. Coat. Technol. 179 (2004) 158-164.

[15] W.L. Xu, T.M. Yue, H.C. Man, C.P. Chan, Surf. Coatings Technol. 200 (2006) 5077-5086.

[16] S.W. Williams, (BAE Systems) Private communication.

[17] P.J. Ryan, Ph.D. Thesis, University of Manchester, 2007.

[18] R.M. Langford, A.K. Petford-Long, J. Vac. Sci. Technol. 19A (2001) 2186-2193.

[19] A. Matsunawa, J.-D. Kim, N. Seto, M. Mizutani, S. Katayama, J. Laser Appl. 10 (1998) 247-254.

[20] B. Yang, Y. Junhui, M.A. Sutton, T.P. Reynolds, Mater. Sci. Eng. A364 (2004) 55-65.

[21] C. Genevois, A. Deschamps, A. Denquin, B. Doisneau-Cottignies, Acta Mater. 53 (2005) 2447-2458.

[22] A.M. Prokhorov, V.I. Konov, I. Ursu, I.N. Mihailescu, Laser Heating of Metals, IOP Publishing Ltd., 1990.

[23] S.A. David, J.M. Vitek, Int. Mater. Rev. 34 (1989) 213-245.

[24] P.B. Prangnell, C.P. Heason, Acta Mater. 53 (2005) 3179-3192.

[25] S. Hori, S. Saji, A. Takehara, J. Jpn. Inst. Light Met. 31 (1981) 793797.

[26] J. Murray, A. Peruzzi, J.P. Abriata, J. Phase Equilibr. 13 (1992) 277-291.

[27] A. Gutierrez, J. Lippold, W. Lin, Mater. Sci. Forum 217-222 (1996) 1691-1696.

[28] G.M. Reddy, A.A. Gokhale, K.S. Prasad, K.P. Rao, Sci. Technol. Weld. Joining 3 (1998) 208-212.

[29] S.C. Gill, M. Zimmermann, W. Kurz, Acta Metall. Mater. 40 (1992) 2895-2906.

[30] W. Kurz, P. Gilgien, Mater. Sci. Eng. A178 (1994) 171-178.

[31] W. Kurz, R. Trivedi, Mater. Sci. Eng. A180 (1994) 46-51.

[32] M.E. Glicksman, Diffusion in Solids, John Wiley and Sons, 2000.

[33] Y. Du, Y.A. Chang, B. Huang, W. Gong, Z. Jin, H. Xu, Z. Yuan, Y. Liu, Y. He, F.-Y. Xie, Mater. Sci. Eng. A363 (2003) 140-151. 